\title{
Genetic Algorithm Based Optimization for Photovoltaics Integrated Building Envelope
}

\author{
Amr Mamdoh Ali Youssef ${ }^{1,2}$, Zhiqiang (John) Zhai ${ }^{1 *}$, Rabee Mohamed Reffat ${ }^{2}$ \\ ${ }^{1}$ Department of Civil, Environmental and Architectural Engineering (CEAE), University of \\ Colorado, UCB 428, ECOT 441, Boulder, CO 80309, USA. \\ ${ }^{2}$ Department of Architectural Engineering,Assiut University, Assiut 71518,Egypt. \\ *Corresponding author:john.zhai@colorado.edu
}

\section{Acknowledgement}

The authors would like to acknowledge the financial support from the Egyptian Ministry of Higher Education for this research. This study is also part of an ongoing research at University of Colorado Boulder funded by US National Science Foundation (EFRI-1038305). 


\begin{abstract}
A growing attention has been paid to building integrated photovoltaics (BIPV) when designing net-zero-energy buildings. Envelope features of large commercial buildings can be properly designed to both enhance PV integration and reduce building energy use. Many studies have been focused on predicting PV performance of designed systems or optimizing building envelope properties to reduce energy consumption. This study introduces an optimization framework using genetic algorithm (GA) via the GenOpt program to determine the best options for building envelope designs to reduce net building energy cost and increase PV utilization capacity/efficiency. A set of envelope design features were tested in this study, such as, building dimensions, window-to-wall-ratio (WWR), orientation, and PV integration placement, upon which the associated PV and building energy cost are evaluated and compared. Cubic commercial buildings commonly found in Egypt were used to demonstrate the application of the proposed optimization process. The developed tool can help designers to determine the optimal envelopes with appropriate BIPV options from both energy and economic perspectives.
\end{abstract}

Keywords: Building Integrated Photovoltaics; Genetic Algorithm; Building Envelope; Energy Consumption; Power Generation 


\section{List of symbols:}

\begin{tabular}{|c|c|}
\hline$B I P V$ & Building integrated Photovoltaics \\
\hline$S A M$ & System Advisor Model (a software tool) \\
\hline eQUEST & the QUick Energy Simulation Tool (a software tool) \\
\hline$W W R$ & Window-to-Wall-Ratio \\
\hline $\boldsymbol{G A}$ & Genetic Algorithm \\
\hline GenOpt & Generic Optimization Program \\
\hline So.i & $i$ denotes to a solution number \\
\hline So.i-i' & $\begin{array}{l}i^{\prime} \text { denotes to a developed case by applying a consecutive optimization on solution } \\
\text { number }(i) \text {. }\end{array}$ \\
\hline Fa. $n$ & $n$ denotes to one of the model facades (as specified in Figure 3 ) \\
\hline L.1, L.2 & The 2 lengths of the model edges (as specified in Figure 3 ) \\
\hline$S A: V$ & Surface area to volume ratio \\
\hline
\end{tabular}

\section{Introduction}

Utilizing photovoltaic (PV) systems in electrifying buildings receives growing attentions in developing net-zero-energy buildings, especially in climate zones with rich solar resources. External façades of commercial buildings, in addition to the roof, are needed for the placement of PV, because roof-mounted PV cannot generate adequate power for single multi-story building demand. For instance, roof-mounted 
PV may generate $404 \mathrm{kWh} /\left(\mathrm{m}^{2} . \mathrm{yr}\right)$ in hot climates under standard test conditions, while commercial buildings require $134 \mathrm{kWh} /\left(\mathrm{m}^{2} . \mathrm{yr}\right)$ in this climate based on ASHRAE standard [1]; the roof thus can only supply three floors of electricity need. PV integration with external facades (rather than using supporting racks) is also appreciated by architects and users for enhanced architectural dynamics and esthetics.

High cost and low efficiency of PV modules are the main challenges in building integrated PV (BIPV) designs. The goal of this study is to explore how to determine the best combinations of envelope characteristics for better BIPV performance and the overall building energy performance. For example, changing the dimension ratios of a cubic building(as a feature) from 1:1:2 (width: length: height) to $1: 2: 1$ with a fixed volume (e.g., $62000 \mathrm{~m}^{3}$ ) as well as other features can achieve $9.8 \%$ net energy saving in a hot climate zone (2A), predicted using eQuest [2]. This study proposes a framework of an optimization procedure-using genetic algorithm (GA) via the GenOpt program - that can determine the best options for various BIPV envelope features, using the energy net consumption and PV economic impact as two optimization criteria. Cubic commercial buildings in Egypt were used to demonstrate the developed optimization process. 
Numerous studies were aiming to optimize building envelope features for better energy performance. Jin et al [3] proposed an optimization algorithm to reach minimum building thermal load using "RHINO" tool. Tuhus-Dubrow and Krarti [4] developed an approach to selecting the optimal values among envelope parameters of residential buildings to minimize energy consumption. Znouda et al [5] presented an optimization method to minimize thermal loads of Mediterranean buildings using pseudo-random. Ouarghi and Krarti [6] examined commercial building envelope shapes using GA and neural network to optimize energy and construction cost. Wang et al [7] presented a multi-objective optimization model that assists in designing economic and environmental green buildings. Caldas and Norford [8] developed an optimization tool to determine building envelope properties that minimize HVAC, lighting energy and their costs.

Few approaches and tools were developed to help in optimizing PV integrations. El-Arini et al [9] proposed an optimization approach to maximizing the power of PV panels using GA with Lagrange multiplier algorithm, focusing on the PV technical variables (e.g., tilt angle, temperature and etc.)."RADIANCE", a computational tool, optimizes urban geometric forms for receiving more solar irradiation [10]. Sui and 
Munemoto [11] developed a simulation program "GRIPVS" to optimize shapes of PV gable roofs towards lower $\mathrm{CO}_{2}$ emission and higher investment value.Efforts to optimization envelope designs for combined focuses of reducing building energy consumption and increasing BIPV electricity generation were not found in the literature.

Youssef et al. [12] proposed an optimization method for BIPV envelope design with a focus on the best orientation (as a variable) for individual BIPV surfaces to maximize solar exposure using sensitive analyses. Building surfaces can then be varied towards those sensitive orientations to generate better alternatives in terms of the received solar exposure as shown in Figure 1. This step is then followed by identifying the most matching PV modules for individual surfaces, upon which the PV power generation rate and the related economic impact are analyzed and compared. The study does not explore the detailed yet critical envelope variables such as dimensions, WWR, etc., which will largely increase the number of the variation cases to be studied. As a result, an optimization algorithm will be inevitable to find best combinations of the design options among numerous alternatives. This new study will also consider the net building energy performance (including both consumption and generation) as the evaluation criteria. The following sections detail 
the updated optimization framework, as well as its relation with the previous framework.

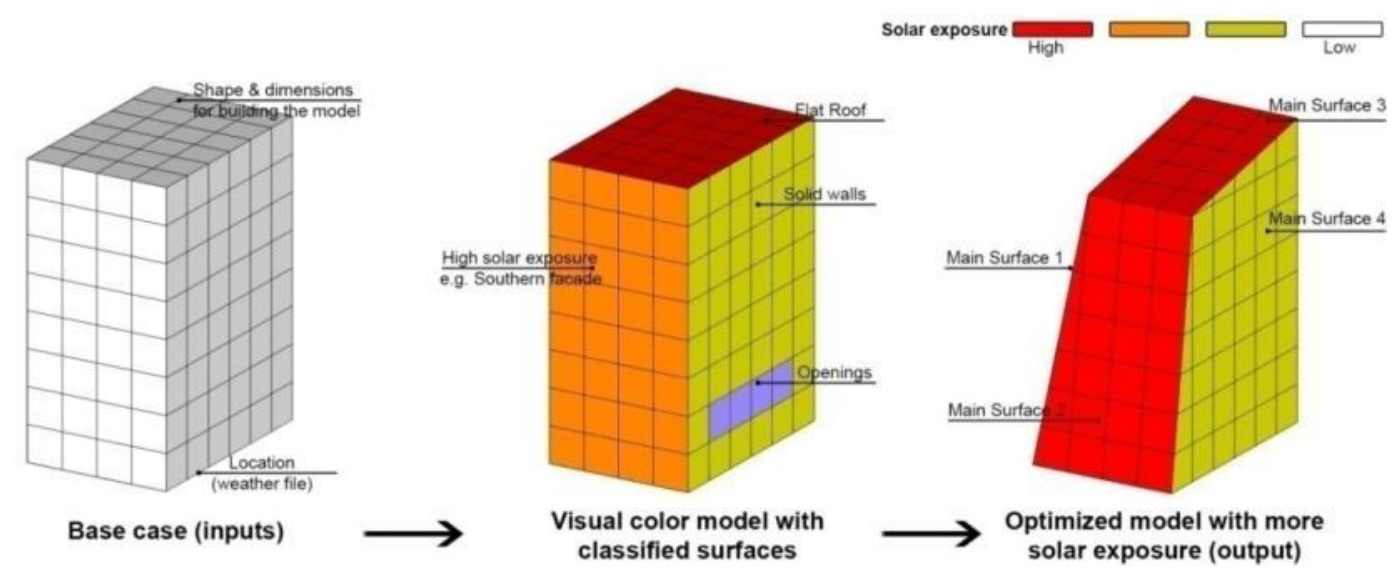

Figure 1: An example of applying the best orientation variations based on the previous optimization method [12]

\section{Proposed Optimization Framework}

The proposed optimization framework consists of two essential steps as shown in Figure 2, followed by an optional step of applying the previous optimization method. 


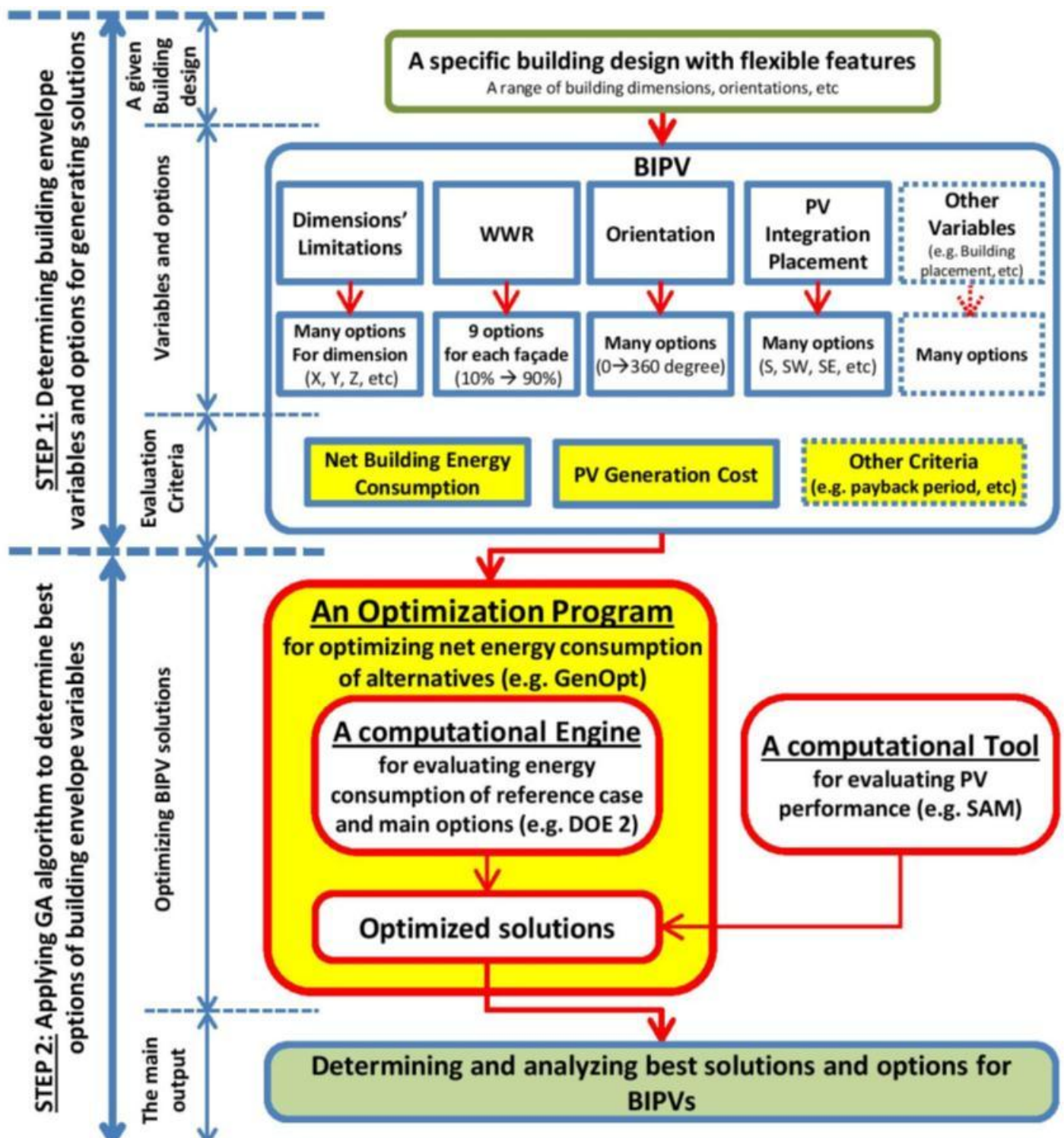

Figure 2: The proposed optimization framework 


\subsection{Step 1: Determining building envelope variables and options for generating possible solutions}

An initial building design in a given location (for climate identification) is a starting point for the optimization. Designers can determine and fix any building envelope variables and their options that meet their design priorities/preferences, such as geometry dimensions, height, orientation, window-to-wall-ratio, potential PV integration placement locations, etc.; each variable contains different options that can be combined to create a comprehensive solution (with one option from each variable); each option has a different effect on PV integration performance and energy consumption. For instance, WWR can be varied among9 options (10\% to 90\%) for each façade, and combining only these options in a simple cubic building can produce 6561 possible solutions $(9 \wedge 4)($ options $\wedge$ facades)for evaluation. Evaluation criteria can be determined based on the design priorities, such as net energy consumption, PV generation cost, PV payback period, etc.

The step-1 achieves a numerical determination for the available variables, options and criteria for optimizing a given building envelope towards the best BIPV designs. 


\subsection{Step 2: Applying GA algorithm to determine the best solutions and options of}

building envelope variables

An optimization algorithm is necessary to identify the best solutions among the generated vast number of potential solutions.GA was chosen as one of the best optimization algorithms for this application based on a detailed comparative analysis. Compared to other algorithms, GA uses a cycle of random exploration that leads to successive reproduction of global solutions, so it can avoid a local maximum or minimum if the population finds better values in other definition domain areas. Moreover, GA performs well in difficult types of functions, such as linear, non-linear, continuous, discontinuous functions and others, and it performs also with large ensembles, complex problems, and large number of probabilistic variables [13]. GA optimization starts with conducting a population of random individual solutions; each solution is a combination of options selected from different variables and has a fitness function (a value) based on evaluation criteria to be optimized. Best solutions in each population can be repeatedly optimized towards better populations using two GA operations: crossover and mutation; crossover operation produces two new solutions by combining two groups of options in the two previous solutions, and mutation operation creates a solution by changing an option or more in one solution; these operations lead to more successful solutions in 
each population [13]. To achieve this process computationally, GenOpt, an optimization program, is employed that can apply GA or other algorithms to minimize the required fitness function that can be evaluated using external simulation programs [14]. In this study, different simulation tools can be used for evaluating solutions, such as DOE-2 [2] and EnergyPlus [15] for evaluating building energy consumption, SAM [16] and RETScreen [17] for predicting PV generation and their economic impact. The final output from this step- 2 is the determination of the best solutions and options from energy consumption and PV generation perspectives. Designers can then use these options in their designs according to their project priorities.

\section{Application of the proposed framework}

A typical commercial building in Egypt was used as an example to demonstrate the application of the proposed optimization. Fossil fuels are the source of $90 \%$ of the electrical power generation in 2010-2011 in Egypt although it has good solar resources to maximize PV technique impacts [18]. Cubic buildings in Egypt represent approximately $80 \%$ of a representative sample survey of 25 commercial buildings in Cairo. Accordingly, cubic commercial buildings in Egypt are used as a starting design for this optimization, as detailed below. 


\subsection{Step 1: Determining building envelope variables and options for generating}

solutions

\subsubsection{Specifying a given design}

The proposed given design is a generic cubic commercial building in Cairo (using Cairo weather file). In this application, surrounding buildings are not considered to extend the limit of optimization application.

\subsubsection{Determining design variables and options of the proposeddesign}

Applicable envelope variables and their options that affect energy consumption and PV performance are illustrated in Table1; a wide range of dimensions and heights were tested to study the influences of different ratios, and building orientations varied within 75 degrees to cover all potential orientation variations for a rectangular shape. Although ASHRAE standard recommends10\%-40\%WWRin the application climate zone for less energy consumption [1], the current practice of WWR in office buildings in Egypt is 60\% [19]. High WWR is also recommended from the architectural perspective for providing view visibility, facades attractiveness and so on. Therefore, the proposed minimum WWR is $40 \%$ in this application, to provide appropriate solutions from both architectural and engineering perspectives. 
Figure 3 illustrates façade's numbers and some other variables. Table 2 illustrates the features of one of the best PV modules for walls' integration; this module was selected from a collected database ${ }^{1}$ that contains 67 PV modules, because it has the best generation performance with appropriate price among other modules. PV integration with glass is not considered in this application because of its high cost $\left(230 \$ / \mathrm{m}^{2}\right)$ [20], even if the average cost of windows in Egypt $\left(100 \$ / \mathrm{m}^{2}\right)^{2}$ was subtracted.

Table 1: Proposed variables and their options in this application

\begin{tabular}{llll}
\hline \multirow{2}{*}{ Variables } & Options & & \\
\cline { 2 - 4 } & Range & Steps & Number of options \\
\hline L.1 (ft) & $150 \rightarrow 400$ & 25 & 11 \\
L.2 (ft) & $150 \rightarrow 400$ & 25 & 11 \\
Height (floors) & $4 \rightarrow 20$ & 2 & 9 \\
Orientation (azimuth) & $0 \rightarrow 75$ & 15 & 6 \\
WWR in Fa.1 (\%) & $40 \% \rightarrow 90 \%$ & $10 \%$ & 6 \\
WWR in Fa.2 (\%) & $40 \% \rightarrow 90 \%$ & $10 \%$ & 6 \\
WWR in Fa.3 (\%) & $40 \% \rightarrow 90 \%$ & $10 \%$ & 6 \\
WWR in Fa.4 (\%) & $40 \% \rightarrow 90 \%$ & $10 \%$ & 6 \\
PV integration in Fa.1 & Yes/No & - & 2 \\
PV integration in Fa. 2 & Yes/No & - & 2 \\
PV integration in Fa.3 & Yes/No & - & 2 \\
PV integration in Fa. 4 & Yes/No & - & 2 \\
\hline
\end{tabular}

${ }^{1}$ This database is detailed in the previous study conducted by the authors (Youssef et al, 2015).

${ }^{2}$ This average was calculated from different windows' manufactories in Egypt. 


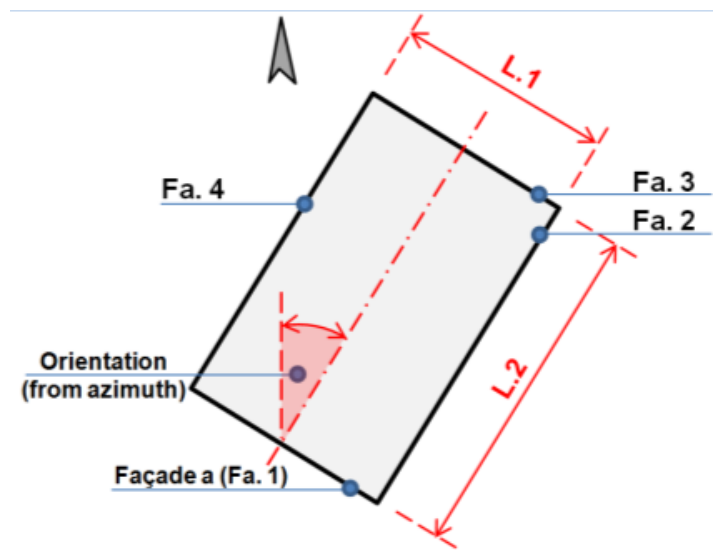

Figure 3: A specification of some variables and facades' numbers

Table 2: PV module for wall integration [21]

PV module specifications

Cell Type

Dimensions $(\mathrm{cm})$

Area $\left(m^{2}\right)$

Power $(W)$

Average Cost $(\$)$

Weight $(\mathrm{kg})$

Max. Power Voltage $(V)$

Max. Power Current $(A)$

Open Circuit Voltage $(V)$

Short Circuit Current $(A)$

Power Tolerance $(\%)$

Color

Other secondary characteristics
Mono-Crystalline

$99.2 * 196 * 0.48$

1.944

$300\left(155 \mathrm{~W} / \mathrm{m}^{2}\right)$

$177\left(91.2 \$ / \mathrm{m}^{2}\right)$

27

36.33

8.33

45

8.9

$\pm 3 \%$

Black

Maximum System Voltage: 1000V DC, Maximum Series Fuse Rating: $15 \mathrm{~A}$

\subsubsection{Determining the required criteria for optimization}

Net building energy performance considering PV generation $\left(\mathrm{kWh} /\left(\mathrm{ft}^{2} \cdot \mathrm{yr}\right)\right)$ and PV generation cost (\$/(MWh.yr)) are considered in this optimization as design criteria. 
3.2. Step 2: Applying GA to determine the best solutions and options of building envelope variables

\subsubsection{Generating and Optimizing BIPV solutions}

Using GA via the GenOpt, DOE-2 and SAM tools, solutions can be optimized computationally to achieve the best fitness function.

3.2.2. Analyzing the best solutions for BIPV optimization (the optimization $\underline{\text { outcome) }}$

A set of the best solutions and options can be determined based on the different evaluation criteria that classify the solutions based on the four practical priorities:

(a) low net energy consumption and PV generation cost;

(b) minimum net energy consumption with PV integration;

(c) minimum PV generation cost with better PV generation; and

(d) minimum net energy consumption without PV integration.

The best solutions according to these priorities were identified as shown in Figure 4 and detailed in the appendix. More specifically, 11 solutions can achieve priority (a) (as illustrated with denoted solution numbers, e.g. So. 800in Figure 4), these solutions cannot be ranked since they have been selected based on two 
inversely proportional criteria (net energy consumption and PV generation cost), while top 30 solutions based on each of the other priorities are determined and analyzed. Few top solutions in each priority may achieve other priorities but in lower levels. For example, So.914 and So.507 are the top solutions based on priority (b), while they are the last top solutions based on priority (c), and both of them achieves priority (a). If the number of selected top solutions has been increased, more solutions that achieve two or three priorities can be found.

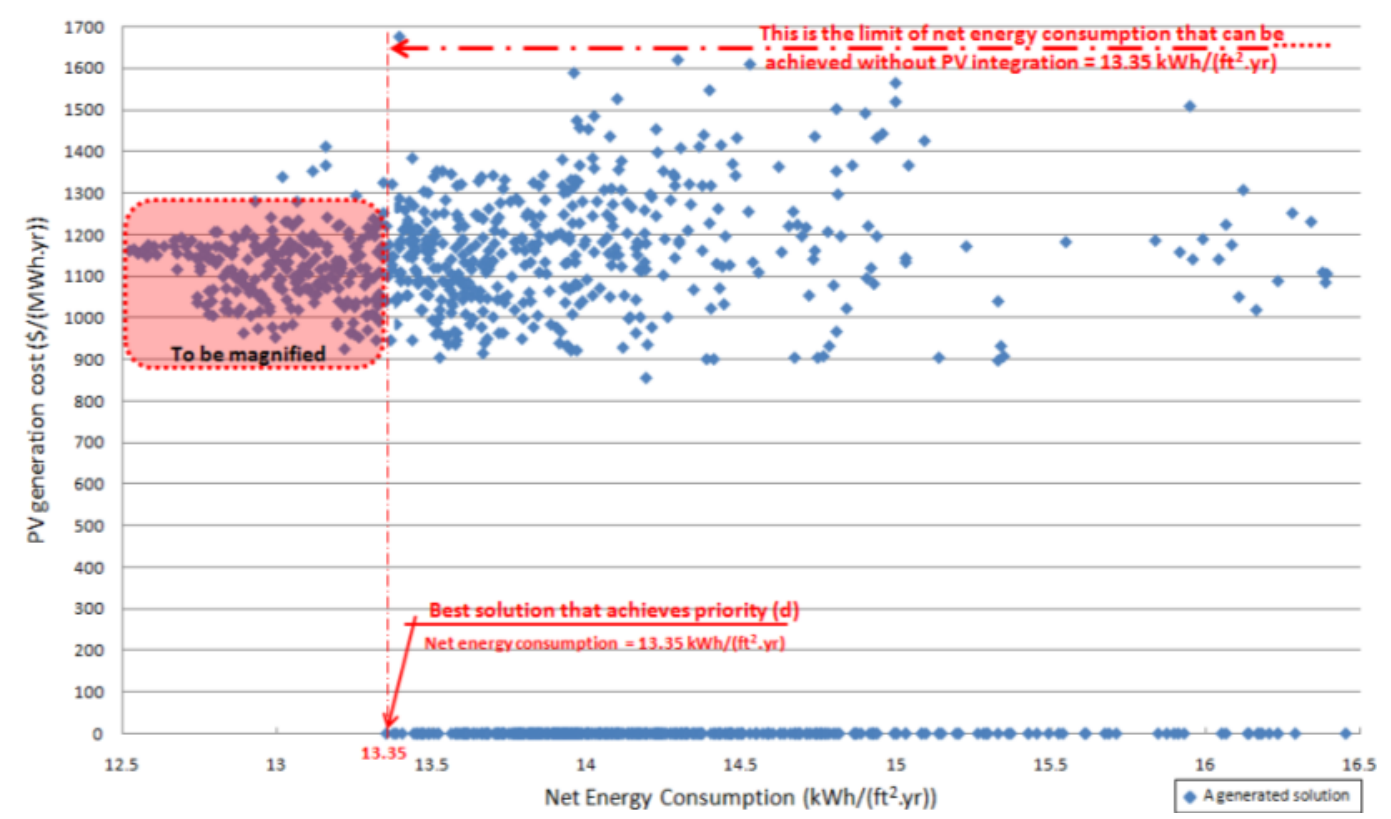

(a) 


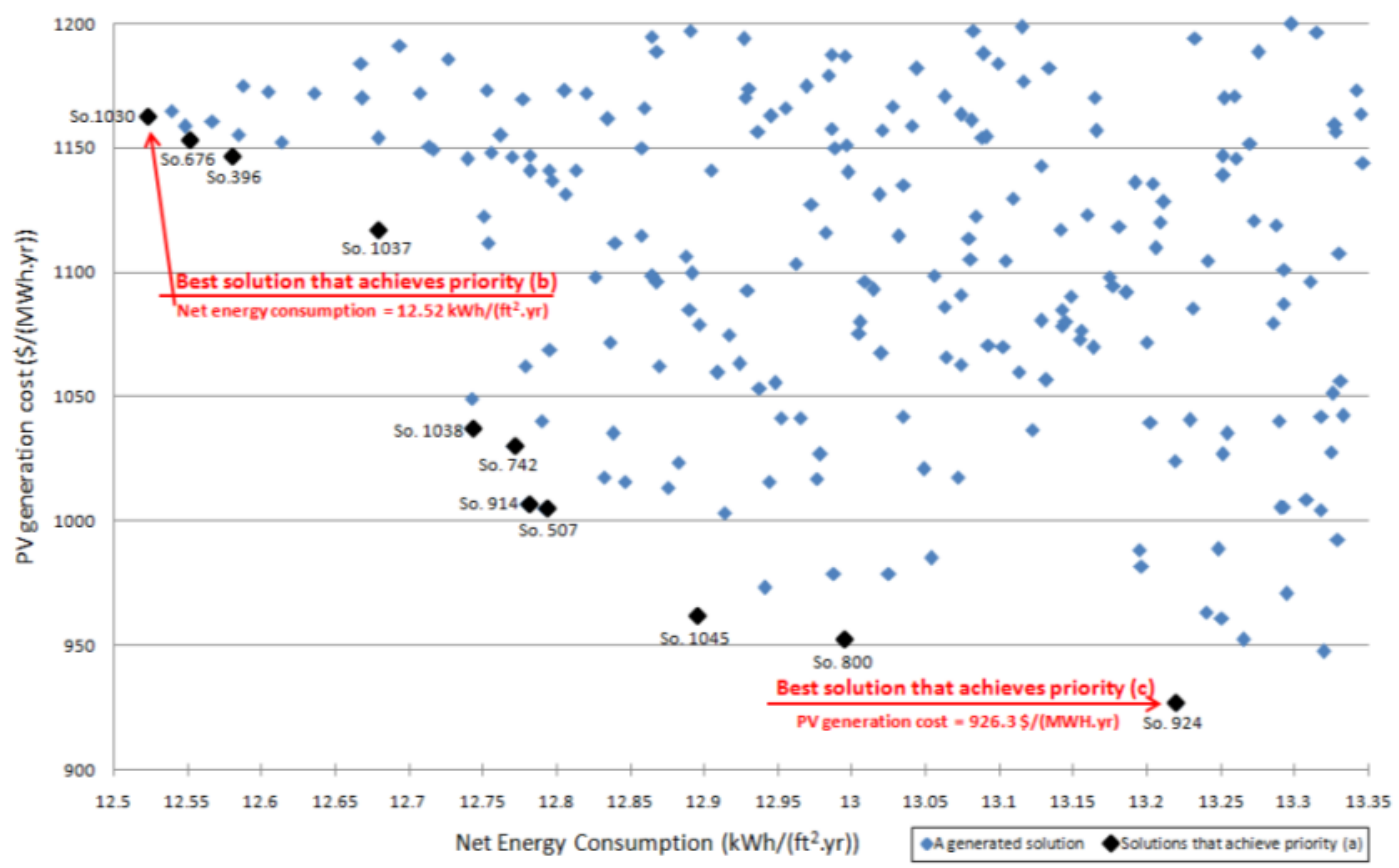

(b)

Figure 4: The evaluation of the optimized solutions: (a) all generated solutions; (b) a magnification on the best optimized solutions.

Common features in the top solutions are more important than those from a single top case, which can provide designers hints on proper envelope and PV decisions- the optimization essential task. The majority of the top solutions, as shown in Figure 5, have the following merits:

a) minimum WWR on all facades except Fa.3 (northern or northern eastern facades) in some cases; variables in these façades have lower effects on energy consumption or PV generation than in other ones; 
b) maximum height; increasing the height reduces the surface-area-to-volume $(\mathrm{SA}: \mathrm{V})$ ratio and the energy consumption accordingly, although it may also reduce PV generation per floor if the roof was included;

c) PV integration on Fa.1 and Fa.2 (facades set towards $90^{\circ}$ to $255^{\circ}$ azimuth angles); these orientations are receiving the most solar exposure in the current application and location; and

d) different orientations; this will provide different possibilities of decreasing the energy consumption, increasing PV generation or both in each case.

Other variable values, such as the $2 \mathrm{D}$ dimensions, vary with the required priorities/criteria, and the relationship between these criteria and the $2 \mathrm{D}$ dimensions of best solutions are illustrated in Figure 6. However, achieving priority (a) requires excluding PV from Fa.3 (facades set towards $0^{\circ}$ to $75^{\circ}$ azimuth angles) in some cases based on the dominant criteria between both involved ones; achieving low net energy consumption and PV generation cost criteria require including and excluding PV integration from that range, respectively; this is more obvious in achieving priority (b) and (c), respectively, since both criteria are separated. Achieving priority (b) requires linear 2D building shapes with integrating PV in all facades except Fa.3 or Fa.4 in some cases (facades set towards $270^{\circ}$ to $75^{\circ}$ azimuth angles), although central 
shapes can provide less energy consumption due to their lower SA:V (as shown in solutions that achieve priority (d)). Solutions that achieve this priority show that PV generation in linear shapes is more than the saving in energy consumption in central shapes, so linear shapes have less net energy consumption after PV integration. However, optimal solution that achieves priority (b) has a horizontal linear shape with PV integration in its all facades; it achieves $12.52 \mathrm{kWh} /\left(\mathrm{ft}^{2} \cdot \mathrm{yr}\right)-$ The optimal net energy consumption in this application. Priority (c) is achieved with high dimensions and excluding PVs from Fa.3 or Fa.4 (facades set towards $270^{\circ}$ to $75^{\circ}$ azimuth angles); the excluded orientation range to achieve this priority is wider than the range for achieving priority (a), because this priority is mainly focusing on PV generation cost as one criterion, while priority (a) includes this criterion beside the net energy consumption as a second one. Also, it is obvious that PV orientation controls mainly this priority, because the same amounts of PV modules have different amount of generation in different orientations. Optimal solution in this priority requires926.3 \$/(MWh.yr), which has a maximum central dimensions and height, $45^{\circ}$ tilt from the azimuth and PV integration in its all facades except the northern eastern one. Priority (d) is achieved in central 2D shapes with high dimensions because of the higher $\mathrm{SA}: \mathrm{V}$ as illustrated before, optimal solution consumes $13.35 \mathrm{kWh} /\left(\mathrm{ft}^{2} . \mathrm{yr}\right)$, which has the maximum central dimensions and height 
also, such optimal solution in priority (c), in addition to the minimum WWR specified for this application. However, better values can be found if the variables' ranges or the application limitations are extended ${ }^{3}$.
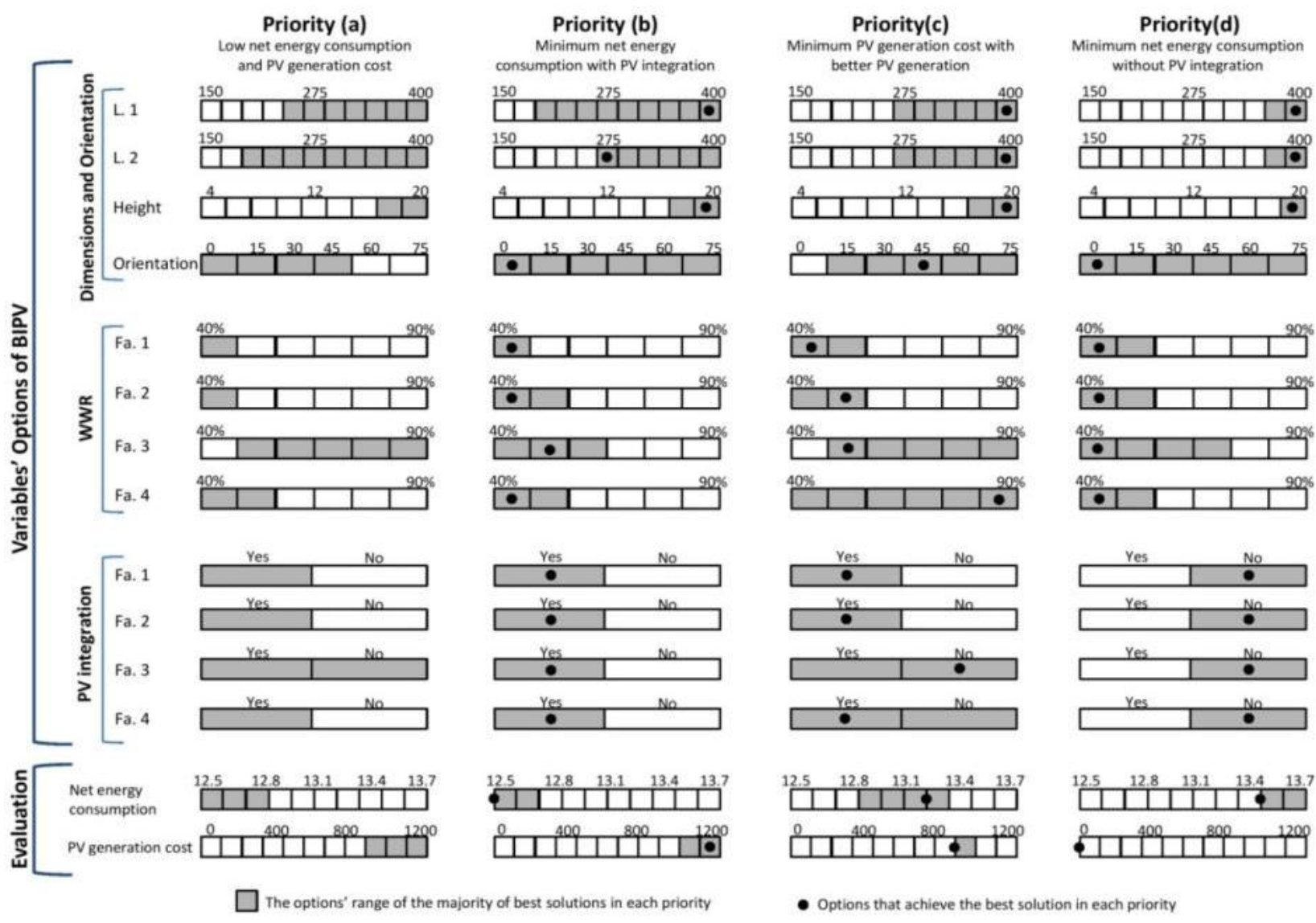

Figure 5: Best solutions and their ranges of options for each design priority

${ }^{3}$ If the minimum WWR specified for this application is $10 \%$, solutions with less energy consumption and higher PV generation than the illustrated current solutions can be found. Specifically, minimum net energy consumption with and without PV integration will be 10.81 and $12.82 \mathrm{kWh} /\left(\mathrm{ft}^{2} . \mathrm{yr}\right)$ in that case, respectively, while minimum PV generation cost with better PV generation will be 824.6 /(MWh.yr), but the WWR will be approximately $10 \%-20 \%$ in the majority of facades and cases, which is not preferred or common practical architecturally as illustrated before. 


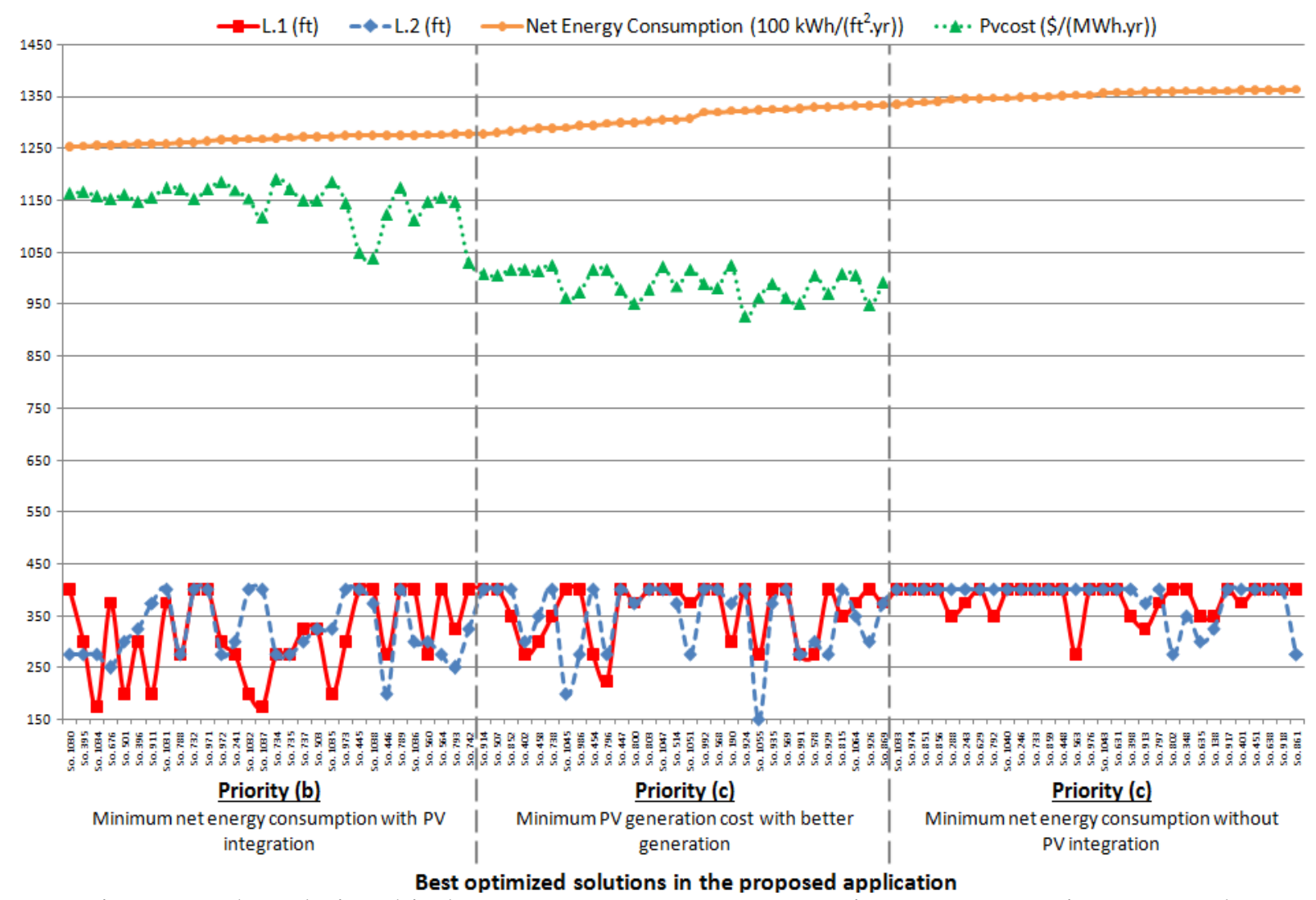

Figure 6: The relationship between net energy consumption, PV generation cost and dimensions of the best optimized solutions

Finally, this current optimization can be followed optionally by the previously developed optimization method by the authors (Youssef et al, 20015) - detailed in the introduction section. Figure 7 shows an example of applying the previously developed method on So.1030 (the top solution in priority (b)and achieves priority (a)); the example shows three cases of applying two of the best orientation variations 
on southern and western facades. As a result, net energy consumption and PV generation cost have been decreased in the three cases. However, not all solutions or models can be applicable or optimized effectively in the previously developed optimization, since some limitations may constraint the applicable cases and generated alternatives. Buildings with low height or near surrounding buildings will make this optional step ineffective. The improvement for applying both optimization processes consecutively will be probable since the optimal features of best alternatives (the output of the current optimization) may be changed again to test another optimization concept. However, the current optimization method cannot be applied after the previous one, because the previous one will generate optimal but fixed building forms, which are also restricted to their position and building surroundings if any, so a lot of variables will not be applicable then, such as dimensions, orientations and others, and the remaining few variables and options can be tested easily using parametric analyses if required. The previous restrictions will still exist if the main variable of the previous method (best orientation variation) was included among the variables in the current optimization. 


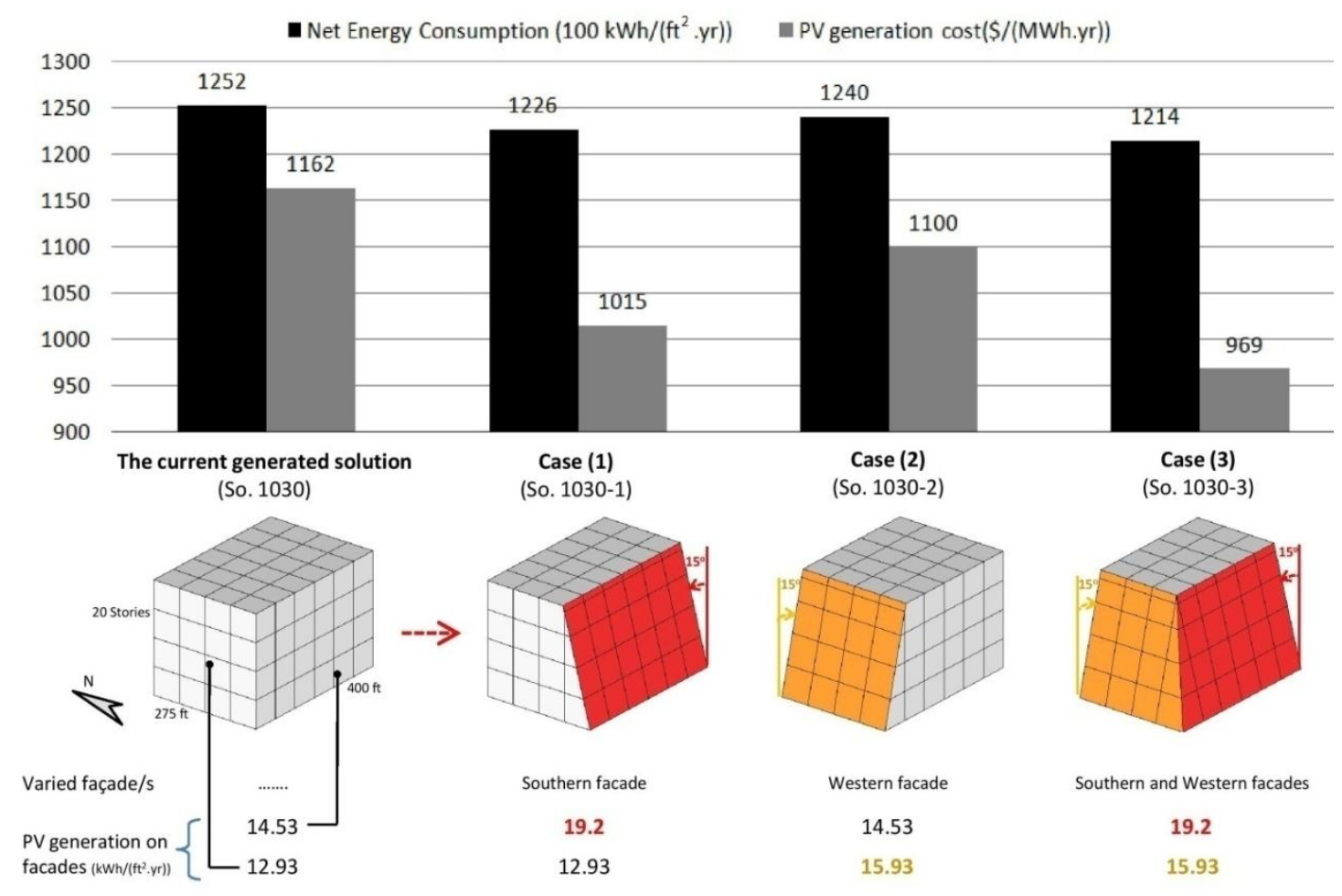

Figure 7: An example of applying the previously developed optimization after the current optimization

\section{Conclusion}

This paper presents and demonstrates a framework of an optimization method to determine the best building envelope designs to both reduce net building energy consumption and best PV utilization. The optimization is implemented using a genetic algorithm (GA) via the available GenOpt optimization program, integrated with other simulation tools. The optimization starts with an initial building shape in a 
specific location. The allowed building envelope variables (e.g. dimensions, orientation, etc.), which may affect energy consumption and PV performance, will be specified by users, along with their associated options/attributes. Specific evaluation criteria (e.g., net energy consumption, PV generation, etc.) will also be identified based on design preferences or priorities. Alternative solutions are automatically created by randomly combining various options of each variable. This optimization framework can be followed by a previously proposed optimization method for BIPV envelopes, which formulates the best orientation variations on BIPV surfaces to maximize solar exposure using sensitive analyses. This improved optimization framework, compared to the previously published method, are: a) focusing on the detailed and critical envelope variables for optimization; b) increasing the applicable shape scenarios and possible alternatives; c) using an automatic optimization algorithm; and d) including the net energy performance in the evaluation criteria.

A typical commercial building in Egypt was used to demonstrate the application of the proposed framework, and a connection among GA optimization algorithm via GenOpt, DOE-2 engine and SAM tool were established to process the proposed optimization computationally and evaluate the solutions. Building dimensions, height, WWR on different facades, orientation and PV integration placements were 
determined as the envelope variables to be optimized, while net building energy consumption $\left(\mathrm{kWh} /\left(\mathrm{ft}^{2} . \mathrm{yr}\right)\right)$ and $\mathrm{PV}$ generation cost (\$/(MWh.yr)) were considered as the evaluation criteria. The application main outcomes are the implications among the best designs that are identified; the majority of the best solutions have minimum WWR on all facades, maximum height and PV integration on facades set towards $90^{\circ}$ to $255^{\circ}$ azimuth angles, while the orientation and the $2 \mathrm{D}$ dimensions are varied based on the required priority. Facades' orientations, and related PV integrations, control the PV generation cost mainly; it is recommended to exclude PV integration on facades set towards $345^{\circ}$ to $75^{\circ}$ azimuth angles if PV economic impact is required, except if more PV generation is needed as well among the designer's priorities. The 2D ratio and dimensions affect the energy consumption; linear 2D shapes with integrated PVs on all facades set towards $90^{\circ}$ to $255^{\circ}$ azimuth angles achieve minimum net energy consumption, while central 2D shape with high dimensions achieves minimum net energy consumption without PV integration. Optimal solutions within different priorities have the similar common and recommended features as illustrated before, optimal net energy consumption with and without PV integration are 12.52 and13.35 $\mathrm{kWh} /\left(\mathrm{ft}^{2} . \mathrm{yr}\right)$, respectively, and minimum $\mathrm{PV}$ generation cost with better generation is $926.3 \$ /(\mathrm{MWh} . \mathrm{yr})$ in this application. However, better values can be found if the application limitations were extended, and 
another previously developed optimization, which focuses on surfaces orientation variations, can follow the current optimization process; better alternatives can be generated accordingly from net energy consumption and PV generation cost perspectives.

This improved optimization method presents a potentially practical tool for designers to find the best building envelope features in order to reduce the net energy consumption with the best PV utilization. More building envelope features and options, beyond what are presented in this paper, can be included, such as facade tilting, positions of windows, shades, neighbors' effect and so on. In addition, the evaluation criteria can be changed based on the design preference or priority, such as, to PV payback period or architectural creativity. A complete computational tool has been developed based on this proposed framework and will be released soon for public test. 
Appendix: The following table illustrates the details of the best optimized solutions;

shaded solutions are the best ones for the opposite shaded priorities (b), (c) and (d), while the best solution based on priority (a) cannot be selected due to including two inversely proportional criteria (net energy consumption and PV generation cost).

\begin{tabular}{|c|c|c|c|c|c|c|c|c|c|c|c|c|c|c|c|c|c|c|}
\hline \multirow{3}{*}{$\begin{array}{c}\text { Solutions } \\
\text { (ranked by net } \\
\text { energy } \\
\text { consumption) }\end{array}$} & \multicolumn{12}{|c|}{ Variables and related options } & \multicolumn{2}{|c|}{ Evaluation Criteria } & \multirow{2}{*}{\multicolumn{4}{|c|}{ Priorities }} \\
\hline & L. 1 & L.2 & Height & $\begin{array}{c}\text { Orientatio } \\
\mathrm{n}\end{array}$ & & WW & २ (\%) & & & PV Inte & gration & & $\begin{array}{c}\text { Net Energy } \\
\text { Consumption }\end{array}$ & $\begin{array}{l}\text { PV generation } \\
\text { cost }\end{array}$ & & & & \\
\hline & $(\mathrm{ft})$ & $(\mathrm{ft})$ & (floors) & (degree) & Fa. 1 & Fa. 2 & Fa. 3 & Fa. 4 & Fa. 1 & Fa. 2 & Fa. 3 & Fa. 4 & $\left(\mathrm{kWh} /\left(\mathrm{ft}^{2} \cdot \mathrm{yr}\right)\right)$ & (\$/(MWh.yr)) & (a) & (b) & (c) & (d) \\
\hline So. 1030 & 400 & 275 & 20 & 0 & $40 \%$ & $40 \%$ & $50 \%$ & $40 \%$ & $\sqrt{ }$ & $\checkmark$ & $\checkmark$ & $\sqrt{ }$ & 12.52 & 1162.5 & & $\checkmark$ & - & - \\
\hline So. 395 & 300 & 275 & 20 & 60 & $40 \%$ & $40 \%$ & $40 \%$ & $40 \%$ & $\checkmark$ & $\checkmark$ & $\checkmark$ & $\checkmark$ & 12.54 & 1164.9 & & $\checkmark$ & - & - \\
\hline So. 1034 & 175 & 275 & 20 & 0 & $40 \%$ & $40 \%$ & $40 \%$ & $40 \%$ & $\checkmark$ & $\checkmark$ & $\checkmark$ & $\checkmark$ & 12.55 & 1158.7 & - & $\checkmark$ & - & - \\
\hline So. 676 & 375 & 250 & 20 & 15 & $40 \%$ & $40 \%$ & $50 \%$ & $40 \%$ & $\checkmark$ & $\checkmark$ & $\checkmark$ & $\checkmark$ & 12.55 & 1152.9 & $\checkmark$ & $\checkmark$ & - & 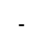 \\
\hline So. 501 & 200 & 300 & 20 & 15 & $40 \%$ & $40 \%$ & $40 \%$ & $40 \%$ & $\checkmark$ & $\checkmark$ & $\checkmark$ & $\checkmark$ & 12.57 & 1160.7 & - & $\checkmark$ & - & - \\
\hline So. 396 & 300 & 325 & 20 & 15 & $40 \%$ & $40 \%$ & $50 \%$ & $40 \%$ & $\checkmark$ & $\checkmark$ & $\checkmark$ & $\checkmark$ & 12.58 & 1146.1 & $\checkmark$ & $\checkmark$ & - & - \\
\hline So. 911 & 200 & 375 & 20 & 15 & $40 \%$ & $40 \%$ & $40 \%$ & $40 \%$ & $\checkmark$ & $\checkmark$ & $\checkmark$ & $\checkmark$ & 12.58 & 1155.3 & & $\checkmark$ & - & - \\
\hline So. 1031 & 375 & 400 & 18 & 75 & $40 \%$ & $40 \%$ & $40 \%$ & $40 \%$ & $\checkmark$ & $\checkmark$ & $\checkmark$ & $\checkmark$ & 12.59 & 1175.1 & & $\checkmark$ & - & - \\
\hline So. 788 & 275 & 275 & 18 & 75 & $40 \%$ & $40 \%$ & $40 \%$ & $40 \%$ & $\checkmark$ & $\checkmark$ & $\checkmark$ & $\checkmark$ & 12.61 & 1172.7 & - & $\checkmark$ & - & - \\
\hline So. 732 & 400 & 400 & 20 & 45 & $40 \%$ & $40 \%$ & $40 \%$ & $50 \%$ & $\checkmark$ & $\checkmark$ & $\checkmark$ & $\checkmark$ & 12.61 & 1152.4 & - & $\checkmark$ & - & - \\
\hline So. 971 & 400 & 400 & 20 & 45 & $40 \%$ & $50 \%$ & $40 \%$ & $40 \%$ & $\checkmark$ & $\checkmark$ & $\checkmark$ & $\checkmark$ & 12.64 & 1172.1 & - & $\checkmark$ & - & - \\
\hline So. 972 & 300 & 275 & 20 & 75 & $40 \%$ & $50 \%$ & $40 \%$ & $40 \%$ & $\checkmark$ & $\checkmark$ & $\checkmark$ & $\checkmark$ & 12.67 & 1183.9 & & $\checkmark$ & - & - \\
\hline So. 241 & 275 & 300 & 20 & 15 & $40 \%$ & $50 \%$ & $40 \%$ & $40 \%$ & $\checkmark$ & $\checkmark$ & $\checkmark$ & $\checkmark$ & 12.67 & 1170.1 & & $\checkmark$ & - & - \\
\hline So. 1032 & 200 & 400 & 18 & 15 & $40 \%$ & $40 \%$ & $40 \%$ & 40 & $\checkmark$ & $\checkmark$ & $\checkmark$ & $\checkmark$ & 12.68 & 53.8 & & $\checkmark$ & - & 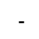 \\
\hline So. 1037 & 175 & 400 & 20 & 0 & $40 \%$ & $40 \%$ & $60 \%$ & $40 \%$ & $\checkmark$ & $\checkmark$ & $\checkmark$ & $\checkmark$ & 12.68 & 1116.3 & & $\checkmark$ & - & - \\
\hline So. 734 & 275 & 275 & 20 & 15 & $50 \%$ & $40 \%$ & $40 \%$ & $40 \%$ & $\checkmark$ & $\checkmark$ & $\checkmark$ & $\checkmark$ & 12.69 & 1191.2 & & $\checkmark$ & - & - \\
\hline So. 735 & 275 & 275 & 20 & 45 & $40 \%$ & $50 \%$ & $40 \%$ & $40 \%$ & $\checkmark$ & $\checkmark$ & $\checkmark$ & $\checkmark$ & 12.71 & 1172.1 & & $\checkmark$ & - & - \\
\hline So. 737 & 325 & 300 & 20 & 15 & $40 \%$ & $40 \%$ & $50 \%$ & $50 \%$ & $\checkmark$ & $\checkmark$ & $\checkmark$ & $\checkmark$ & 12.71 & 1150.5 & & $\checkmark$ & - & - \\
\hline So. 503 & 325 & 325 & 20 & 15 & $40 \%$ & $40 \%$ & $50 \%$ & $50 \%$ & $\checkmark$ & $\checkmark$ & $\checkmark$ & $\checkmark$ & 72 & 4 & & $\checkmark$ & - & - \\
\hline So. 1035 & 200 & 325 & 20 & 45 & $50 \%$ & $40 \%$ & $40 \%$ & $40 \%$ & $\checkmark$ & $\checkmark$ & $\checkmark$ & $\checkmark$ & 12.73 & 1185.6 & - & $\checkmark$ & - & - \\
\hline So. 973 & 300 & 400 & 20 & 15 & $40 \%$ & $40 \%$ & $50 \%$ & $50 \%$ & $\checkmark$ & $\checkmark$ & $\checkmark$ & $\checkmark$ & 12.74 & 1145.5 & & $\checkmark$ & - & - \\
\hline So. 445 & 400 & 400 & 20 & 60 & $40 \%$ & $40 \%$ & $40 \%$ & $60 \%$ & $\checkmark$ & $\checkmark$ & $\checkmark$ & - & 12.74 & 1049.0 & - & $\checkmark$ & - & - \\
\hline So. 1038 & 400 & 375 & 20 & 15 & $40 \%$ & $40 \%$ & $90 \%$ & $40 \%$ & $\checkmark$ & $\checkmark$ & $\checkmark$ & $\checkmark$ & 12.74 & 1037.1 & & $\checkmark$ & - & - \\
\hline So. 446 & 275 & 200 & 18 & 15 & $40 \%$ & $40 \%$ & $60 \%$ & $40 \%$ & $\checkmark$ & $\checkmark$ & $\checkmark$ & $\checkmark$ & 12.75 & 1122.5 & & $\checkmark$ & - & - \\
\hline So. 789 & 400 & 400 & 20 & 45 & $50 \%$ & $40 \%$ & $40 \%$ & $50 \%$ & $\checkmark$ & $\checkmark$ & $\checkmark$ & $\checkmark$ & 12.75 & 1173.2 & & $\checkmark$ & - & 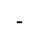 \\
\hline So. 1036 & 400 & 300 & 20 & 60 & $40 \%$ & $40 \%$ & $50 \%$ & $60 \%$ & $\checkmark$ & $\checkmark$ & $\checkmark$ & $\checkmark$ & 12.75 & 1112.0 & & $\checkmark$ & - & - \\
\hline So. 793 & 325 & 250 & 20 & 45 & $40 \%$ & $50 \%$ & $50 \%$ & $40 \%$ & $\checkmark$ & $\checkmark$ & $\checkmark$ & $\checkmark$ & 12.77 & 1146.3 & - & $\checkmark$ & - & - \\
\hline So. 742 & 400 & 325 & 20 & 15 & $40 \%$ & $40 \%$ & $90 \%$ & $40 \%$ & $\checkmark$ & $\checkmark$ & $\checkmark$ & $\checkmark$ & 12.77 & 1030.2 & $\checkmark$ & $\checkmark$ & - & - \\
\hline So. 914 & 400 & 400 & 20 & 30 & $40 \%$ & $40 \%$ & $50 \%$ & $50 \%$ & $\checkmark$ & $\checkmark$ & - & $\checkmark$ & 12.78 & 1007.0 & $\checkmark$ & $\checkmark$ & $\checkmark$ & - \\
\hline So. 507 & 400 & 400 & 20 & 15 & $40 \%$ & $40 \%$ & $60 \%$ & $50 \%$ & $\checkmark$ & $\checkmark$ & - & $\checkmark$ & 12.79 & 1005.2 & $\checkmark$ & $\checkmark$ & $\checkmark$ & - \\
\hline So. 852 & 350 & 400 & 20 & 30 & $40 \%$ & $40 \%$ & $60 \%$ & $50 \%$ & $\checkmark$ & $\checkmark$ & - & $\checkmark$ & 12.83 & 1017.4 & - & - & $\checkmark$ & - \\
\hline So. 402 & 275 & 300 & 20 & 15 & $40 \%$ & $40 \%$ & $90 \%$ & $40 \%$ & $\checkmark$ & $\checkmark$ & - & $\checkmark$ & 12.85 & 1015.8 & - & - & $\checkmark$ & 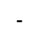 \\
\hline So. 458 & 300 & 350 & 20 & 15 & $40 \%$ & $50 \%$ & $70 \%$ & $40 \%$ & $\checkmark$ & $\checkmark$ & - & $\checkmark$ & 12.88 & 1013.5 & - & - & $\checkmark$ & - \\
\hline So. 738 & 350 & 400 & 20 & 60 & $40 \%$ & $40 \%$ & $50 \%$ & $70 \%$ & $\checkmark$ & $\checkmark$ & $\checkmark$ & - & 12.88 & 1023.5 & - & - & $\checkmark$ & - \\
\hline So. 1045 & 400 & 200 & 18 & 30 & $40 \%$ & $40 \%$ & $50 \%$ & $40 \%$ & $\checkmark$ & $\checkmark$ & - & $\checkmark$ & 12.90 & 962.1 & $\checkmark$ & - & $\checkmark$ & - \\
\hline So. 986 & 400 & 275 & 20 & 30 & $40 \%$ & $50 \%$ & $50 \%$ & $50 \%$ & $\checkmark$ & $\checkmark$ & - & $\checkmark$ & 12.94 & 973.1 & - & - & $\checkmark$ & - \\
\hline So. 454 & 275 & 400 & 20 & 60 & $40 \%$ & $40 \%$ & $40 \%$ & $70 \%$ & $\checkmark$ & $\checkmark$ & - & $\checkmark$ & 12.94 & 1015.9 & - & - & $\checkmark$ & - \\
\hline So. 796 & 225 & 275 & 20 & 75 & $40 \%$ & $40 \%$ & $40 \%$ & $70 \%$ & $\checkmark$ & $\checkmark$ & $\checkmark$ & - & 12.98 & 1016.8 & - & - & $\checkmark$ & \\
\hline
\end{tabular}




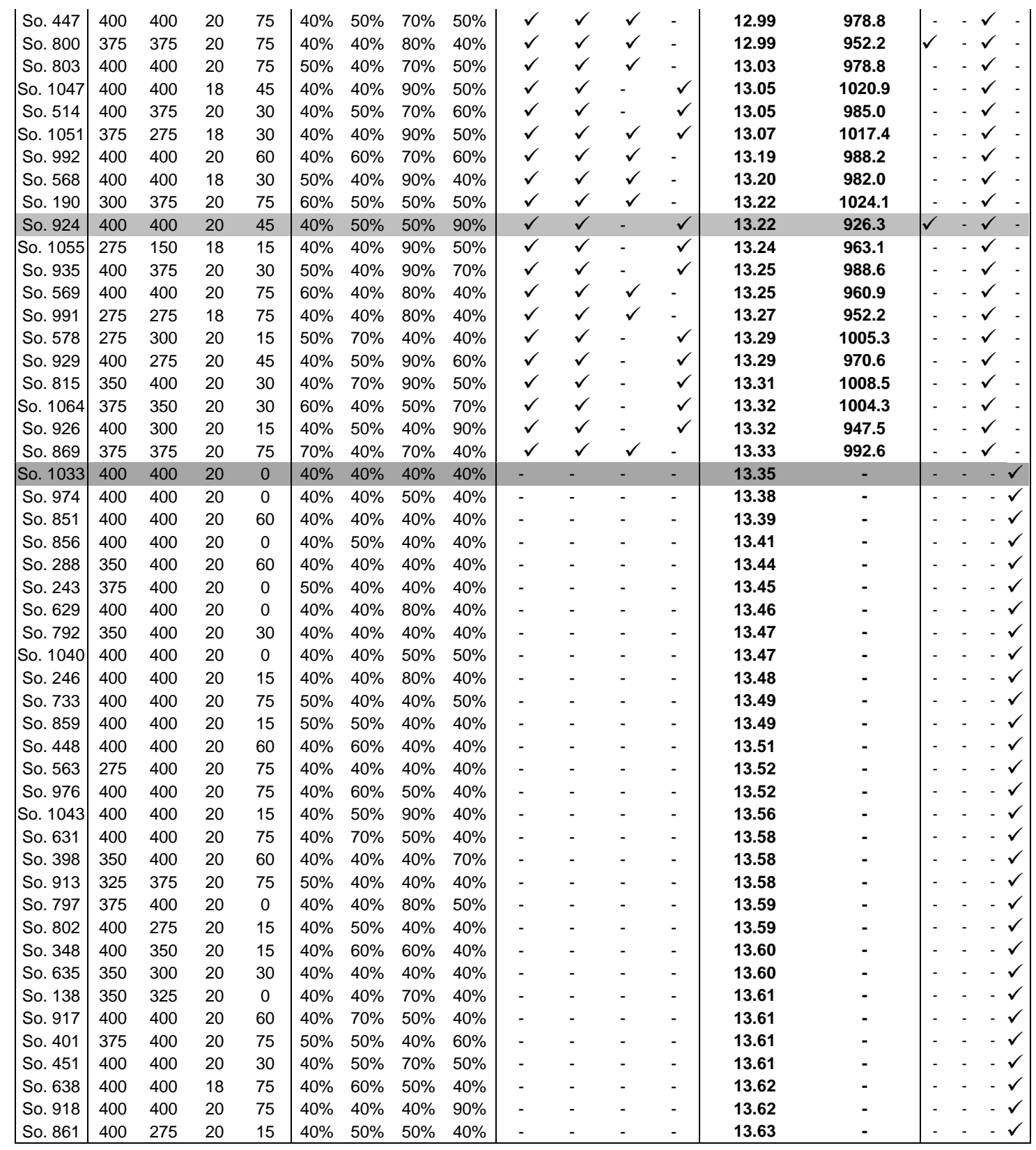

Page 28 from31 


\section{References}

[1] ASHRAE (2007).ANSI/ASHRAE/IESNA Standard 90.1-2007.Final Qualitative Determination.

[2] DOE-2 (2014) DOE-2 based software homepage, eQuest. Available via http://www.doe2.com/equest. Accessed at 20 Oct. 2014.

[3] Jin, J.T., Cho, H.J. and Jeong, J.W. (2012).Optimization of Freeform Building Shape Using Genetic Algorithm. Proceedings of the 1st Asia International Building Performance Simulation Association (IBPSA) Conference and Exhibition (ASim2012), Shanghai, China. Available via: http://www.ibpsa.org/proceedings/asim2012/0019.pdf. Accessed 15 Apr 2016.

[4] Tuhus-Dubrow D, Krarti M (2010). Genetic-algorithm based approach to optimize building envelope design for residential buildings. Energy and Buildings 45: 1574-1581.

[5] Znouda E, Ghrab-Morcos N, Hadj-Alouane A (2007). Optimization of Mediterranean building design using genetic algorithms. Energy and Buildings 39:148-153.

[6] Ouarghi R, Krarti M (2006). Building Shape Optimization Using Neural Network and Genetic Algorithm Approach. ASHRAE Transactions 112: 484-491. Available via: http://web.b.ebscohost.com/abstract. Accessed at: 15 Apr 2016.

[7] Wang W, Zmeureanua R, Rivard H (2004). Applying multi-objective genetic algorithms in green building, design optimization. Building and Environment 40:1512-1525.

[8] Caldas LG, Norford LK (2003). Genetic algorithms for optimization of building envelope. Journal of Solar Energy Engineering 125:343-351.

[9] El-Arini MM, Othman AM, Fathy A (2013). A new optimization approach for maximizing the photovoltaic panel power based on genetic algorithm and lagrange multiplier algorithm. International journal of photoenergy 2103:1-12. Available via : 
http://www.cisjournal.org/journalofcomputing/archive/vol4no1/vol4no1_13.pdf. Accessed at 15 Apr 2016.

[10] Kampf JH, Robinson D (2010). Optimization of building form for solar energy utilization using constrained evolutionary algorithms. Energy and Buildings 42: 807-814.

[11] Sui J, Munemoto J (2007). Shape Study on a Green Roof Integrated Photovoltaic System for Biobjective Optimization of Investment Value and $\mathrm{CO} 2$ Emission. Asian Architecture and Building Engineering 6: 307-314.

[12] Youssef AMA, Zhai Z, Reffat, RM (2015). Design of Optimal Building Envelopes with Integrated Photovoltaics. Building Simulation 8(3): 353-366. Available via: http://link.springer.com/article/10.1007\%2Fs12273-015-0214-y. Accessed at 15 Apr 2016.

[13] Mardle S, Pascoe S (1999). An overview of genetic algorithms for the solution of optimisation problems. Computers in Higher Education Economics Review (CHEER) 13-1. Available via: https://www.economicsnetwork.ac.uk/cheer/ch13_1/ch13_1p16.htm. Accessed at 28April 2015.

[14] Wetter M. (2011). GenOpt generic optimization program user manual, version 3.1.0. Berkeley, CA: Lawrence Berkeley National Laboratory Report. Available via: http://simulationresearch.lbl.gov/GO/download. Accessed at 15 Feb. 2015.

[15] EERE (2014).EnergyPlus Energy Simulation Software, Energy Efficiency \& Renewable Energy, US Department of Energy.Avaliable via: http://apps1.eere.energy.gov/buildings/energyplus. Accessed at 5 Nov. 2014.

[16] NREL (2014) System Advisor Model, SAM.Available via https://sam.nrel.gov. Accessed at 20 Oct. 2014.

[17] NRCAN (2014) Natural Resources Canada, RETScreen International. Available viahttp:// www.retscreen.net/ang/home.php. Accessed at 20 Oct. 2014. 
[18] Ministry of Electricity and Energy (2011). Annual Report. Cairo, Egypt: Ministry of Electricity and Energy.

[19] Hanna GB (2011). Energy Efficiency Building Codes for Egypt. Journal of Energy and Power $\begin{array}{llll}\text { Engineering } & 5 & \text { Available via: }\end{array}$ http://davidpublishing.com/davidpublishing/upfile/12/30/2011/ 2011123002335205.pdf. Accessed at 28April 2015.

[20] SolarOR (2015). SolarORBeeHive PV Facade. Available via: http:// Solaror.com. Accessed at 15 Feb 2015.

[21] ES (2015).Electrical Supplies. Available via: http://www.sourcingelectricals.com/300W-mono-likesolar-module-solar-panel-PV-module-30033740/. Accessed at 15 Feb 2015. 